\title{
Predictors of smoking cessation behavior among Bangladeshi adults: findings from ITC Bangladesh survey
}

\author{
Abu S. Abdullah ${ }^{1,2,3^{*}}$, Pete Driezen ${ }^{4}$, Anne C. K. Quah ${ }^{4}$, Nigar Nargis ${ }^{5}$ and Geoffrey T. Fong ${ }^{4,6}$
}

\begin{abstract}
Background: Research findings on the predictors of smoking cessation behavior identified in Western countries may not be generalizable to smokers in the Southeast Asian countries (i.e., Bangladesh). This study examined the factors associated with smoking cessation behavior (quit attempts and smoking cessation) among a representative sample of Bangladeshi adults.

Methods: Data from Wave 1 (2009) and Wave 2 (2010) of the International Tobacco Control (ITC) Survey in Bangladesh, a face-to-face survey of adult smokers, were analysed. Households were sampled using a stratified multistage design and interviewed using a structured questionnaire. Respondents included in the study are 1,861 adult daily smokers (cigarette only or dual use of cigarette and bidi) in the Wave 1 survey who completed the Wave 2 follow up.

Results: Of the smokers $(N=1,861), 98 \%$ were male, $18 \%$ illiterate, $78 \%$ married and $42 \%$ were aged 40 or above; $89 \%$ were cigarette smokers and $11 \%$ were dual users (cigarette \& bidi). Overall, $21.8 \%$ of the baseline smokers made quit attempts (that is, making at least one quit attempt that lasted for at least 24 hours) during the 11- to 12-month interval between Waves 1 and 2 with only $4.1 \%$ quitting successfully (that is, smokers who had stopped smoking for at least 6 months at the time of the Wave 2 survey). Significant predictors of attempts to quit included: residing areas outside Dhaka $(O R=3.41)$, being aged 40 or older $(O R=1.53)$, having a monthly income of above BDT10,000 (US\$126) versus below BDT 5,000 (US\$63) (OR=1.57), intending to quit sometime in the future $(O R=1.73)$. Respondents not working indoors/outside the home were less likely to have made a quit attempt than those with no workplace restrictions on smoking $(O R=0.62)$. Predictors of successful smoking cessation included: being aged 40 or older $(O R=3.11)$, perceiving self-rated health as good or excellent $(O R=2.40)$, and an increased level of self-efficacy $(O R=1.75)$. Smokers who made a quit attempt not so recently ( 6 months ago or earlier) were less likely to quit than those who made a more recent (in last 6 months) quit attempt ( $O R=0.23)$.

Conclusion: Among Bangladeshi smokers, different factors were associated with quit attempt or successful cessation. Population based smoking cessation programs should take these factors into consideration in the design of smoking cessation interventions. At the same time, measures are necessary to encourage more smokers to make quit attempts.
\end{abstract}

Keywords: Smoking, Quit attempt, Smoking cessation, Bangladeshi adults

\footnotetext{
* Correspondence: Asm.Abdullah@graduate.hku.hk

${ }^{1}$ Department of General Internal Medicine, Boston Medical Center, Boston

University School of Medicine, 801 Massachusetts Avenue, 2nd Floor (MISU),

Boston, Massachusetts 02118, USA

${ }^{2}$ Global Health Program, Duke Kunshan University, Kunshan, Jiangsu Province

215347, China

Full list of author information is available at the end of the article
}

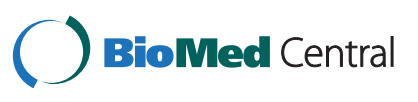

(c) 2015 Abdullah et al. Open Access This article is distributed under the terms of the Creative Commons Attribution 4.0 International License (http://creativecommons.org/licenses/by/4.0/), which permits unrestricted use, distribution, and reproduction in any medium, provided you give appropriate credit to the original author(s) and the source, provide a link to the Creative Commons license, and indicate if changes were made. The Creative Commons Public Domain Dedication waiver (http://creativecommons.org/publicdomain/zero/1.0/) applies to the data made available in this article, unless otherwise stated. 


\section{Introduction}

Tobacco use is the leading cause of preventable death and disease worldwide and is estimated to kill more than 5 million people each year [1]. Public health strategies to combat tobacco-induced illnesses have aimed at reducing uptake and promoting smoking cessation. Given the limitations of population-based programs to reduce smoking initiation among the public [2], the need to provide cessation support to those who continue to smoke is substantial. Therefore, identification of factors that could facilitate cessation is important in the design of evidence-based smoking cessation interventions.

With a population of 150 million, Bangladesh is one of the top ten countries in the world having a high smoking prevalence, where over 22 million adults smoke [3]. The overall smoking (cigarettes, bidis, and hookah) prevalence has increased in Bangladesh from $20.9 \%$ in 2004 to $22.0 \%$ in 2010 [4]. Studies also identified a 9-percentage point increase of smokingattributable deaths among Bangladeshi adults; from $16 \%$ in 2004 [5] to $25 \%$ in 2010 [6]. This high rate of tobacco-attributable mortality underscores the rapidly growing health and economic burden of tobacco use in Bangladesh. To address this growing epidemic of tobacco-induced deaths, there is an urgent need to reduce tobacco use in Bangladesh which will require curtailing initiation of tobacco use and promotion of smoking cessation.

Previous research [7-10] has identified factors associated with smoking cessation, including low nicotine dependence, male gender, higher educational attainment, being married, being older, consuming fewer cigarettes per day, and not having other smokers in the household. However, little is known about the factors that are associated with smoking cessation among the Bangladeshi population. The identification of Bangladesh-specific factors is needed to assess the need for and nature of smoking cessation services that would be appropriate for Bangladesh and other developing countries with similar socioeconomic characteristics.

The aim of this study is to examine the factors associated with smoking cessation behavior (that is, quit attempts and smoking cessation) among a nationally representative sample of Bangladeshi adults.

\section{Methods}

\section{Sample}

The data for this study come from the first two waves of the International Tobacco Control (ITC) Policy Evaluation Bangladesh Survey. The ITC Bangladesh Survey is a prospective cohort survey of a nationally representative sample of adult smokers and nonsmokers (aged 15 and older) conducted in all six administrative divisions of Bangladesh [11, 12]. In total,
1,792 cigarette smokers and 229 dual users (defined as smokers who smoke both cigarettes and bidis) were recruited in Wave 1 from the non-tribal and non-slum areas of Bangladesh. Of these, 1,656 cigarette smokers (92\%) and 205 dual users $(90 \%)$ were successfully followed in Wave 2. The analysis reported here is based only on the sample of smokers recruited in Wave 1 and retained in Wave 2. Data were collected using face-to-face interviews and sampling weights were computed so that results are representative of the population of adult Bangladeshi smokers. The details of the ITC Bangladesh Survey are described elsewhere $[4,12,13]$.

\section{Measures}

Attempts to quit smoking (i.e. quit attempts) and successful cessation formed the primary outcome measures used in this study. Quit attempts were defined as making any serious attempt to quit smoking, between the waves, that lasted for at least 24 hours. Successful cessation in Wave 2 was defined as making a quit attempt between the waves and not smoking for six months or longer as reported by the respondents.

\section{Predictor variables}

The ITC Bangladesh Survey measures a wide range of domains related to tobacco use and tobacco control. Details of the questionnaire are described elsewhere [12] but relevant domains include socio-demographic characteristics as well as behavioural, cognitive, attitudinal, environmental and motivational measures. All independent variables were measured in Wave 1 and used to predict cessation attempts and successful cessation in Wave 2.

\section{Socio-demographic measures}

Respondents' socio-demographic backgrounds were characterized using sex, age, religion (Muslim vs. non-Muslim), residence (Dhaka vs. areas outside Dhaka) and marital status (married vs. not). The ITC Bangladesh Survey also assesses respondents' education (illiterate, $1-8$ years and 9 years or more), monthly household income $(<5,000 \mathrm{BDT}$, $5,000-10,000 \mathrm{BDT},>10,000 \mathrm{BDT}$ and not reported) (exchange rate: $1 \mathrm{US} \$=79 \mathrm{BDT}$ ), and the number of smokers living in each respondent's home.

\section{Smoking behaviors}

Smokers were classified on the basis of whether they smoked on a daily or non-daily basis. In addition, smokers reported their usual daily consumption of cigarettes and bidis. Typical consumption was treated as a continuous variable; for cigarette smokers, total consumption was defined using the number of cigarettes smoked per day. For dual users, total consumption was defined as the number of cigarettes and then number of bidis smoked per day. Smokers were also asked how 
recently they tried to quit smoking (never tried, within the last six months and six months ago or longer). Finally, smokers reported the age at which they started smoking. This information was used to compute the number of years each respondent smoked, using respondent's age at recruitment into the ITC Bangladesh Survey.

\section{Beliefs}

This study assessed respondents' self-reported health (average or poor vs. good or excellent), their level of addiction to cigarettes (not addicted, somewhat addicted or very addicted), intentions to quit smoking (no plans, sometime in the future or within the next six months) and beliefs about their confidence (self-efficacy) to quit (measured on a five point scale ranging from not at all sure to extremely sure). With the exception of selfefficacy, all belief variables were treated as categorical measures in the analysis.

\section{Environmental factors}

Smokers' surrounding environments were assessed on the basis of the number of smokers living in their homes (1, 2 and 3 or more) and whether they received any support to quit smoking (defined as advice, information or referral to quit given by a physician or health care provider). Respondents were also asked about whether they themselves had implemented any smoking restrictions in their homes (no restrictions, partial restrictions or complete restrictions). In addition, smokers who worked outside the home were asked about workplace smoking restrictions; smokers were classified as not working outside the home, not working indoors, having no or only partial workplace restrictions and having complete workplace smoking bans.

\section{Motivational factors}

Smokers' motivation to quit smoking was assessed by measuring (a) their overall opinion towards cigarette smoking, (b) their overall opinion towards bidi smoking, (c) their expectations of future health effects, if they quit smoking (outcome expectancy), (d) their worry about the health consequences of smoking, and (e) whether they have favourable attitudes toward smoking. Opinions toward smoking were classified as good or neutral, bad, and very bad. Outcome expectancy, worries about health and favourable attitudes toward smoking were measured as continuous variables. Outcome expectancy was assessed using the question "How much do you think you would benefit from health and other gains if you were to quit smoking cigarettes permanently in the next 6 months?" Responses ranged from $1=$ "not at all" to $5=$ "extremely". Worries about health were defined using the average of two measures: "How worried are you, if at all, that smoking cigarettes will damage your health in the future?" and "To what extent, if at all, has smoking cigarettes lowered your quality of life?" Each of these measures was assessed using a four-point scale (worry: $1=$ "not at all worried", 2 = "a little worried", $3=$ "moderately worried", and 4 = "very worried"; quality of life: $1=$ "not at all", 2 = "just a little", 3="a fair amount", 4="a great deal"). Favorable attitude toward smoking was also assessed as the average of two measures: (a) "enjoy smoking too much to give it up" and (b) "smoking cigarettes is an important part of your life". Each of these measures was assessed using a five-point Likert scale ranging from $1=$ "strongly agree" to $5=$ "strongly disagree". All of the continuous motivation measures were coded so that higher scores reflected greater amounts of each measure.

\section{Reasons to quit}

Reasons to quit smoking included smokers' concern about the effect of cigarette smoke on non-smokers, believing that Bangladeshi society disapproves of smoking, the price of cigarettes, workplace smoking restrictions, smoking restrictions in public places, free or low-cost smoking cessation medications, advertisements about the health risks of smoking, warning labels on cigarette packs, setting an example for children, friends and family disapprove of smoking, and the rising costs of essentials including food or fuel. Each measure was classified on the basis of whether or not it was a reason to quit smoking.

\section{Statistical Analysis}

Descriptive statistics appropriate for complex survey data were used to estimate the prevalence of cessation attempts and successful cessation by Wave 2. Bivariate associations between quit status, defined as no attempts to quit, tried but unsuccessful and successful cessation, and each of the categorical measures were tested using the Rao-Scott $\chi^{2}$ statistic. Mean levels of the continuous predictors were estimated for each quit status category. Differences between categories were tested using a univariate linear regression model, accounting for the complex survey design.

Binary logistic regression models were then used to examine associations between independent predictors and (1) attempts to quit and (2) successful cessation.

The first set of models examining predictors of quit attempts were based on all smokers. Following Borland, et al., [14], smokers who tried to quit but were not successful and smokers who quit successfully were classified as having tried to quit. These models estimated the odds of making an attempt to quit (vs. not making an attempt). Models predicting successful cessation were based on only those smokers who tried to quit to estimate the odds of successful cessation (vs. trying, but failing, to quit). 
Regression models were built using a backward selection procedure. All covariates were entered into a preliminary model while socio-demographic covariates were forced into each model. Then, each behavioural, belief, environmental and motivational covariate was removed from the preliminary model, one variable at a time. In each step, the Akaike information criterion (AIC) was computed and the best fitting sub-model was selected (i.e., the sub-model having the smallest AIC statistic after removing a covariate). The procedure was repeated until removal of variables no longer improved model fit (i.e., no sub-model resulted in a smaller value for the AIC statistic). The final selected model was then re-fit using only the selected covariates in order to use as many observations as possible to predict each of the cessation outcomes. The selection procedure was conducted using logistic regression procedures appropriate for complex survey data in order to account for the multi-stage sampling design. All results presented here are weighted using a longitudinal weight that adjusts for attrition in order to represent the population of adult smokers aged 15 and older in Bangladesh. The analysis was conducted using SAS version 9.4.

\section{Results}

Of 1,861 daily smokers present in both Waves 1 and 2 (Table 1), the majority $(85 \%)$ were recruited from nontribal areas outside Dhaka. The vast majority of smokers were male (98\%), married (78 \%), Muslim (87\%), smoked cigarettes exclusively (89\%), and had monthly household incomes of more than 5,000 BDT (1US\$ $=79$ BDT) $(74.7 \%)$. Almost three quarters of selected smokers came from homes having two or more smokers. Overall, $4 \%$ of adult smokers quit smoking for at least six months in 2010 while another $22 \%$ tried to quit but were not successful.

Bivariate associations between demographic variables and Wave 2 quit status (quit attempts and successful quitting) showed that older age and area of residence were associated with quit status. Specifically, older (aged 40 or above) smokers were significantly more likely to try to quit $(25.2 \%)$ or quit successfully $(6.4 \%)$ than younger (aged $15-39)$ smokers $\left(20.5 \%\right.$ and $2.7 \%$, respectively) $\left(x^{2}=\right.$ 15.10; $\mathrm{p}<0.001)$. Subjects recruited from outside of Dhaka were significantly more likely to try to quit $(22.9 \%)$ or quit successfully $(4.4 \%)$ than Dhaka $(13.7 \%$ and $1.3 \%$, respectively) $\left(X^{2}=8.86 ; p=0.012\right)$. (Data not shown)

Tables 2 and 3 examine bivariate associations between Wave 2 quit status (quit attempts and successful quitting) and behavioural, belief, environmental and motivational factors. Many of these factors were not significantly associated with quit status. However, quit recency, perceived addiction, quit intentions and workplace smoking restrictions were significantly associated with quit status (Table 2). In
Table 1 Sample characteristics of smokers recruited in Wave 1 and followed to Wave 2 (unweighted; $n=1861$ )

\begin{tabular}{|c|c|c|}
\hline & $\%$ & (Freq.) \\
\hline \multicolumn{3}{|l|}{ Area } \\
\hline Dhaka & 15.1 & $(281)$ \\
\hline Areas outside Dhaka & 84.9 & (1580) \\
\hline \multicolumn{3}{|l|}{ Sex } \\
\hline Male & 98.1 & $(1826)$ \\
\hline Female & 1.9 & $(35)$ \\
\hline \multicolumn{3}{|l|}{ Age group } \\
\hline Younger than 40 & 57.8 & (1076) \\
\hline 40 or older & 42.2 & (785) \\
\hline \multicolumn{3}{|l|}{ Marital status } \\
\hline No married & 22.2 & (413) \\
\hline Married & 77.8 & $(1444)$ \\
\hline \multicolumn{3}{|l|}{ Religion } \\
\hline Non-Muslim & 12.6 & (234) \\
\hline Muslim & 87.4 & (1626) \\
\hline \multicolumn{3}{|l|}{ Education } \\
\hline Illiterate & 18.6 & (346) \\
\hline 1 to 8 years & 55.3 & (1026) \\
\hline $9+$ years & 26.1 & $(484)$ \\
\hline \multicolumn{3}{|l|}{ Income } \\
\hline$<5,000$ BDT & 15.8 & (294) \\
\hline 5,000 to $10,000 \mathrm{BDT}$ & 42.7 & (794) \\
\hline$>10,000$ BDT & 32.2 & (599) \\
\hline Not reported & 9.3 & $(174)$ \\
\hline \multicolumn{3}{|l|}{ Total smokers in home } \\
\hline 1 & 25.7 & (478) \\
\hline 2 & 52.8 & (982) \\
\hline 3 or more & 21.5 & $(401)$ \\
\hline \multicolumn{3}{|l|}{ Type of smoker } \\
\hline Exclusively cigarettes & 89.0 & $(1656)$ \\
\hline Dual user & 11.0 & (205) \\
\hline \multicolumn{3}{|c|}{ Mean daily amount smoked (SD) } \\
\hline Exclusively cigarettes & 9.60 & $( \pm 6.16)$ \\
\hline Dual user & 13.32 & $( \pm 8.82)$ \\
\hline \multicolumn{3}{|l|}{ Quit status } \\
\hline Did not try to quit & 74.1 & (1379) \\
\hline Tried unsuccessfully & 21.8 & $(406)$ \\
\hline Quit successfully & 4.1 & (76) \\
\hline
\end{tabular}

BDT = Bangladeshi Taka; 1US\$ = 79BDT

addition, cigarette consumption (mean numbers smoked daily) and attitudes toward smoking differed by quit status (Table 3). A greater percentage of smokers who made previous attempts to quit had tried again by wave 2 compared to smokers who never tried to quit. Specifically, almost 
Table 2 Behavioural, belief, environmental and motivational factors associated with Wave 2 quit status, ITC Bangladesh (weighted results)

\begin{tabular}{|c|c|c|c|c|c|c|c|c|c|}
\hline & \multicolumn{6}{|c|}{ Wave 2 quit status } & \multirow[b]{3}{*}{ Rao-Scott $x^{2}$} & \multirow[b]{3}{*}{ DF } & \multirow[b]{3}{*}{$\mathrm{p}$ value } \\
\hline & \multicolumn{2}{|c|}{ Did not try to quit } & \multicolumn{2}{|c|}{ Tried, unsuccessful } & \multicolumn{2}{|c|}{ Quit successfully } & & & \\
\hline & Freq. & $\%$ & Freq. & $\%$ & Freq. & $\%$ & & & \\
\hline \multicolumn{10}{|l|}{ Smoking behaviours } \\
\hline \multicolumn{10}{|l|}{ Type of smoker } \\
\hline Exclusively cigarettes & 1220 & 74.6 & 368 & 21.6 & 68 & 3.8 & 0.40 & 2 & 0.818 \\
\hline Dual user & 159 & 77.6 & 38 & 19.6 & 8 & 2.8 & & & \\
\hline \multicolumn{10}{|l|}{ Any tobacco use } \\
\hline Cigarettes \& other smoked or smokeless & 161 & 77.8 & 38 & 19.4 & 8 & 2.8 & 1.80 & 4 & 0.772 \\
\hline Cigarettes \& smokeless & 227 & 73.2 & 80 & 21.6 & 20 & 5.2 & & & \\
\hline Exclusively cigarettes & 991 & 75.0 & 288 & 21.6 & 48 & 3.4 & & & \\
\hline \multicolumn{10}{|l|}{ Cigarettes/day } \\
\hline$<=10 /$ day & 945 & 74.2 & 278 & 21.8 & 59 & 4.0 & 2.43 & 4 & 0.658 \\
\hline 11-20/day & 337 & 75.2 & 109 & 21.7 & 14 & 3.1 & & & \\
\hline 21+/day & 66 & 82.9 & 16 & 16.4 & 2 & 0.7 & & & \\
\hline \multicolumn{10}{|l|}{ Quit recency } \\
\hline Never tried to quit & 896 & 78.6 & 214 & 17.9 & 42 & 3.5 & 25.67 & 4 & $<0.001$ \\
\hline Recently (in last 6 months) & 161 & 66.7 & 67 & 27.2 & 15 & 6.1 & & & \\
\hline Not so recently (6 months ago or earlier) & 293 & 68.9 & 121 & 28.6 & 16 & 2.5 & & & \\
\hline \multicolumn{10}{|l|}{ Quit beliefs } \\
\hline \multicolumn{10}{|l|}{ Self-rated health } \\
\hline Poor/average health & 633 & 72.2 & 202 & 24.3 & 35 & 3.5 & 5.97 & 2 & 0.051 \\
\hline Good/excellent health & 744 & 77.4 & 204 & 18.7 & 41 & 3.8 & & & \\
\hline \multicolumn{10}{|l|}{ Perceived addiction } \\
\hline Not addicted & 128 & 65.4 & 42 & 28.4 & 12 & 6.2 & 8.46 & 4 & 0.076 \\
\hline Somewhat addicted & 833 & 74.7 & 254 & 21.8 & 46 & 3.5 & & & \\
\hline Very addicted & 408 & 78.4 & 107 & 18.4 & 17 & 3.2 & & & \\
\hline \multicolumn{10}{|l|}{ Quit intentions } \\
\hline No plan to quit & 682 & 79.8 & 169 & 17.5 & 25 & 2.6 & 33.34 & 4 & $<0.001$ \\
\hline Sometime in the future & 437 & 67.1 & 181 & 29.3 & 31 & 3.6 & & & \\
\hline Within the next 6 months & 134 & 70.8 & 40 & 21.5 & 12 & 7.7 & & & \\
\hline \multicolumn{10}{|l|}{ Environmental factors } \\
\hline \multicolumn{10}{|l|}{ Total smokers in home } \\
\hline 1 & 365 & 75.7 & 91 & 20.5 & 22 & 3.8 & 1.45 & 4 & 0.835 \\
\hline 2 & 724 & 75.1 & 217 & 21.0 & 41 & 3.9 & & & \\
\hline 3 or more & 290 & 73.6 & 98 & 23.5 & 13 & 2.9 & & & \\
\hline \multicolumn{10}{|l|}{ Cessation support } \\
\hline No advice & 1213 & 75.6 & 354 & 20.9 & 62 & 3.5 & 2.55 & 2 & 0.279 \\
\hline Advice/information/referral to quit & 166 & 69.5 & 52 & 25.4 & 14 & 5.1 & & & \\
\hline \multicolumn{10}{|l|}{ Workplace smoking restrictions } \\
\hline No restrictions & 205 & 74.5 & 70 & 22.2 & 8 & 3.3 & 1.95 & 4 & 0.745 \\
\hline Partial/complete restrictions & 181 & 72.0 & 64 & 24.9 & 9 & 3.1 & & & \\
\hline Does not work indoors/does not work & 964 & 75.7 & 258 & 20.3 & 59 & 4.0 & & & \\
\hline
\end{tabular}


Table 2 Behavioural, belief, environmental and motivational factors associated with Wave 2 quit status, ITC Bangladesh (weighted results) (Continued)

\begin{tabular}{|c|c|c|c|c|c|c|c|c|c|}
\hline \multicolumn{10}{|c|}{ Smoking restrictions in the home } \\
\hline No restrictions & 527 & 75.6 & 163 & 21.2 & 28 & 3.1 & 4.14 & 4 & 0.388 \\
\hline Partial restrictions & 213 & 80.7 & 54 & 17.0 & 8 & 2.4 & & & \\
\hline Completely banned & 610 & 72.0 & 185 & 23.6 & 38 & 4.4 & & & \\
\hline \multicolumn{10}{|l|}{ Motivational factors } \\
\hline \multicolumn{10}{|c|}{ Overall opinion towards cigarette smoking } \\
\hline Good/neutral & 66 & 77.7 & 13 & 17.4 & 5 & 4.9 & 1.31 & 4 & 0.860 \\
\hline Bad & 1019 & 74.9 & 305 & 21.7 & 50 & 3.4 & & & \\
\hline Very bad & 286 & 74.2 & 87 & 21.5 & 21 & 4.3 & & & \\
\hline \multicolumn{10}{|c|}{ Overall opinion towards bidi smoking } \\
\hline Good/neutral & 35 & 85.8 & 7 & 12.5 & 1 & 1.7 & 4.73 & 4 & 0.316 \\
\hline Bad & 875 & 76.1 & 244 & 20.4 & 42 & 3.5 & & & \\
\hline Very bad & 462 & 72.1 & 153 & 23.7 & 33 & 4.2 & & & \\
\hline
\end{tabular}

$30 \%$ of smokers who ever tried to quit in Wave 1 reported making additional attempts to quit in Wave 2. Another $6.1 \%$ of smokers who, in Wave 1, tried to quit within the last six months managed to quit successfully by Wave 2 (Table 2). A larger percentage of smokers who planned to quit sometime in the future in Wave 1 reported making additional attempts to quit by wave 2, compared to smokers who never tried to quit in Wave 1 (29.3\% vs $17.5 \%$, respectively). Smokers having more definite plans to quit in Wave 1 were more likely to have quit successfully by Wave 2: $7.7 \%$ of smokers who planned to quit within the next six months quit successfully by Wave 2 compared to less than
$4 \%$ of smokers who had no plans or non-definite plans to quit in Wave 1 (Table 2). Other factors significantly related to quit status included daily cigarette consumption and holding favorable attitudes toward smoking (Table 3).

To better understand the predictors of (a) attempts to quit smoking and (b) successful smoking cessation among Bangladeshi smokers, weighted multi-variable logistic regression was used to model the independent predictors of each outcome controlling for socio-demographic covariates. As shown in Table 4, significant predictors of attempts to quit included: residing outside of Dhaka $(\mathrm{OR}=3.41)$, being aged 40 or older $(\mathrm{OR}=1.53)$, having a

Table 3 Mean levels of behavioural, belief and motivational factors by Wave 2 quit status (weighted)

\begin{tabular}{|c|c|c|c|c|c|c|c|c|c|c|}
\hline & \multicolumn{6}{|c|}{ Wave 2 quit status } & \multirow[b]{3}{*}{ F Test } & & \multirow[b]{3}{*}{ DF } & \multirow[b]{3}{*}{$\mathrm{p}$ value } \\
\hline & \multicolumn{2}{|c|}{ Did not try to quit } & \multicolumn{2}{|c|}{ Tried, unsuccessful } & \multicolumn{2}{|c|}{ Quit successfully } & & & & \\
\hline & $\mathrm{N}$ & Mean & $\mathrm{N}$ & Mean & $\mathrm{N}$ & Mean & & & & \\
\hline \multicolumn{11}{|l|}{ Behavioural factors } \\
\hline \multicolumn{11}{|l|}{ Cigarettes/day } \\
\hline Mean cig/day & 1348 & 10.08 & 403 & 9.52 & 75 & 7.65 & 8.20 & 2 & 32 & 0.001 \\
\hline \multicolumn{11}{|l|}{ Mean no. years smoked } \\
\hline Mean no. years smoked & 1379 & 18.15 & 406 & 20.44 & 76 & 23.06 & 2.29 & 2 & 32 & 0.117 \\
\hline \multicolumn{11}{|l|}{ Quit beliefs } \\
\hline \multicolumn{11}{|l|}{ Self-efficacy } \\
\hline Mean self-efficacy & 1363 & 2.14 & 404 & 2.16 & 76 & 2.37 & 0.72 & 2 & 32 & 0.496 \\
\hline \multicolumn{11}{|l|}{ Motivational factors } \\
\hline \multicolumn{11}{|l|}{ Outcome expectancy } \\
\hline Mean & 1345 & 2.86 & 390 & 2.97 & 69 & 2.85 & 1.31 & 2, & 32 & 0.284 \\
\hline \multicolumn{11}{|l|}{ Worries about health } \\
\hline Mean & 1340 & 2.18 & 389 & 2.17 & 73 & 2.30 & 1.42 & 2 & 32 & 0.256 \\
\hline \multicolumn{11}{|c|}{ Favourable attitude towards cigarette smoking } \\
\hline Mean & 1330 & 3.08 & 393 & 2.97 & 70 & 2.86 & 7.05 & 2 & 32 & 0.003 \\
\hline
\end{tabular}


Table 4 Odds of making an attempt to quit smoking by Wave 2 (weighted; $n=1643$ )

\begin{tabular}{|c|c|c|c|c|}
\hline & \multirow[b]{2}{*}{ OR $(95 \% \mathrm{Cl})$} & \multicolumn{3}{|c|}{ Wald $x^{2}$ Test } \\
\hline & & $\overline{x^{2 a}}$ & DF & $p$ value \\
\hline \multicolumn{5}{|l|}{ Area } \\
\hline Dhaka & 1.00 & 11.98 & 1 & $<0.001$ \\
\hline Areas outside Dhaka & $3.41(1.70,6.82)$ & & & \\
\hline \multicolumn{5}{|l|}{ Sex } \\
\hline Male & 1.00 & 2.82 & 1 & 0.093 \\
\hline Female & $2.24(0.87,5.73)$ & & & \\
\hline \multicolumn{5}{|l|}{ Age group } \\
\hline Younger than 40 & 1.00 & 9.61 & 1 & 0.002 \\
\hline 40 or older & $1.53(1.17,2.00)$ & & & \\
\hline \multicolumn{5}{|l|}{ Education } \\
\hline Illiterate & 1.00 & 1.69 & 2 & 0.429 \\
\hline 1 to 8 years & $1.08(0.67,1.75)$ & & & \\
\hline $9+$ years & $1.22(0.89,1.68)$ & & & \\
\hline \multicolumn{5}{|l|}{ Income } \\
\hline$<5,000$ BDT & 1.00 & 5.37 & 3 & 0.147 \\
\hline 5,000 to 10,000 BDT & $1.11(0.72,1.73)$ & & & \\
\hline$>10,000$ BDT & $1.57(1.07,2.30)$ & & & \\
\hline Not reported & $1.14(0.57,2.25)$ & & & \\
\hline \multicolumn{5}{|l|}{ Self-rated health } \\
\hline Poor/average health & 1.00 & 2.74 & 1 & 0.098 \\
\hline Good/excellent health & $0.78(0.59,1.05)$ & & & \\
\hline \multicolumn{5}{|l|}{ Intentions to quit } \\
\hline No plans to quit & 1.00 & 14.86 & 2 & $<0.001$ \\
\hline Sometime in the future & $1.73(1.28,2.32)$ & & & \\
\hline Within the next 6 months & $1.32(0.76,2.28)$ & & & \\
\hline \multicolumn{5}{|l|}{ Advice to quit } \\
\hline No advice & 1.00 & 0.18 & 1 & 0.669 \\
\hline Advice/info/referral to quit & $1.11(0.70,1.75)$ & & & \\
\hline \multicolumn{5}{|c|}{ Workplace smoking restrictions } \\
\hline No restrictions & 1.00 & 9.10 & 2 & 0.011 \\
\hline Partial/complete restrictions & $0.87(0.56,1.36)$ & & & \\
\hline $\begin{array}{l}\text { Does not work indoors/ } \\
\text { outside home }\end{array}$ & $0.62(0.43,0.90)$ & & & \\
\hline \multicolumn{5}{|l|}{ Home smoking restrictions } \\
\hline No restrictions & 1.00 & 4.97 & 2 & 0.083 \\
\hline Partial restrictions & $0.92(0.59,1.43)$ & & & \\
\hline Completely banned & $1.74(0.95,3.19)$ & & & \\
\hline
\end{tabular}

BDT = Bangladeshi Taka; 1 US $\$=79 B D T$

${ }^{\mathrm{a} O m n i b u s}$ test

monthly income of above BDT 10,000 versus below BDT $5,000(\mathrm{OR}=1.57)$, having an intention to quit sometime in the future versus having no plans to quit $(\mathrm{OR}=1.73)$. Respondents not working indoors/outside the home were less likely to have made a quit attempt than those with no workplace restrictions on smoking $(\mathrm{OR}=0.62)$. As shown in Table 5, predictors of successful smoking cessation included: being aged 40 or older $(\mathrm{OR}=3.11)$, perceiving self-rated health as good or excellent $(\mathrm{OR}=2.40)$, and an increased level of self-efficacy $(\mathrm{OR}=1.75)$, where a one point increase in smoker's self-efficacy increased the odds of successful cessation by $80 \%$. Smokers who made a quit

Table 5 Odds of successful cessation (6 months or longer) by Wave 2 (weighted; $n=454$ )

\begin{tabular}{|c|c|c|c|c|}
\hline & \multirow[b]{2}{*}{ OR $(95 \%$ Cl) } & \multicolumn{3}{|c|}{ Wald $x^{2}$ Test } \\
\hline & & $\overline{x^{2 a}}$ & DF & $p$ value \\
\hline \multicolumn{5}{|l|}{ Area } \\
\hline Dhaka & 1.00 & 2.76 & 1 & 0.097 \\
\hline Areas outside Dhaka & $2.09(0.88,4.99)$ & & & \\
\hline \multicolumn{5}{|l|}{ Sex } \\
\hline Male & 1.00 & 0.10 & 1 & 0.747 \\
\hline Female & $0.60(0.03,13.01)$ & & & \\
\hline \multicolumn{5}{|l|}{ Age group } \\
\hline Younger than 40 & 1.00 & 13.75 & 1 & $<0.001$ \\
\hline Aged 40+ & $3.11(1.71,5.67)$ & & & \\
\hline \multicolumn{5}{|l|}{ Education } \\
\hline Illiterate & 1.00 & 0.53 & 2 & 0.768 \\
\hline 1 to 8 years & $1.01(0.48,2.13)$ & & & \\
\hline $9+$ years & $1.27(0.61,2.68)$ & & & \\
\hline \multicolumn{5}{|l|}{ Income } \\
\hline$<5,000$ BDT & 1.00 & 4.39 & 3 & 0.222 \\
\hline 5,000 to 10,000 BDT & $0.35(0.12,1.04)$ & & & \\
\hline$>10,000$ BDT & $0.39(0.14,1.05)$ & & & \\
\hline Not reported & $0.44(0.09,2.11)$ & & & \\
\hline \multicolumn{5}{|l|}{ Quit recency } \\
\hline Recently (in last 6 months) & 1.00 & 11.29 & 2 & 0.004 \\
\hline Never tried to quit & $0.75(0.34,1.66)$ & & & \\
\hline $\begin{array}{l}\text { Not so recently ( } 6 \text { months } \\
\text { ago or earlier) }\end{array}$ & $0.23(0.09,0.62)$ & & & \\
\hline \multicolumn{5}{|l|}{ Self-rated health } \\
\hline Poor/average health & 1.00 & 7.91 & 1 & 0.005 \\
\hline Good/excellent health & $2.40(1.30,4.43)$ & & & \\
\hline \multicolumn{5}{|l|}{ Self-efficacy } \\
\hline 1 unit increase & $1.75(1.29,2.38)$ & 13.06 & 1 & $<0.001$ \\
\hline \multicolumn{5}{|l|}{$\begin{array}{l}\text { Information/advice/referral } \\
\text { to quit smoking }\end{array}$} \\
\hline No advice to quit & 1.00 & 2.87 & 1 & 0.091 \\
\hline $\begin{array}{l}\text { Advice/info/referral } \\
\text { to quit }\end{array}$ & $2.27(0.88,5.85)$ & & & \\
\hline \multicolumn{5}{|l|}{ Outcome expectancy } \\
\hline 1 unit increase & $0.82(0.56,1.20)$ & 1.05 & 1 & 0.306 \\
\hline
\end{tabular}

$B D T=$ Bangladeshi Taka; 1 US\$ $=79 B D T$

${ }^{\mathrm{a} O m n i b u s}$ test 
attempt not so recently (6 months ago or earlier) were less likely to quit than those who made a more recent (in last 6 months) quit attempt $(\mathrm{OR}=0.23)$.

\section{Discussion}

This is the first nationally representative survey to study predictors of smoking cessation behavior among Bangladeshi adults. Our findings suggest that several factors are associated with quitting attempts and successful quitting among adult smokers from Bangladesh. The proportion of Bangladeshis who successfully quit smoking (4.3\%) was almost identical to the natural quit rate among other populations, such as Chinese adult smokers (4.4 \%) [15]. However, one-fifth of adult smokers made quit attempts in this study though they were not successful, underscoring the need for organized smoking cessation programs. Previous research has shown that making attempts to quit is a strong predictor of successful quitting [16].

Consistent with findings from previous research $[17,18]$, in this study, older (aged 40 or above) smokers were more likely to make quit attempts or quit successfully. This may be due to the fact that older smokers experienced more health problems and visited more healthcare professionals and received repeated advise to quit smoking, which encouraged them to make quit attempts or quit successfully $[19,20]$. In a Hong Kong study, older smokers wanted to set an example by quitting smoking for the future young generation [21]. The findings that smokers from areas outside the capital city of Dhaka had made more quit attempts than smokers who were residing inside the city underscore the fact that the limited tobacco use prevention and cessation campaigns in the city are not reaching the target population to encourage them to try to quit. The high quit intention among residents living outside Dhaka may also suggest the low level of income among these residents that limits their ability to buy cigarettes and, hence, they may make greater efforts to quit.

In this study, higher income smokers (monthly income above BDT 10,000) made more successful quit attempts compared to those with a monthly income of less than BDT 5,000. This suggests the need to target low income smokers with cessation interventions. In a study by Haas et al. [22], a proactive smoking cessation outreach program was effective in reaching low income smokers with smoking cessation services.

Although in previous studies home [23] or workplace [24] smoking restrictions had a significant effect on quitting attempts or quitting, the effect of these variables was not significant in the current study. In this study, respondents not working indoors/outside the home were less likely to have made a quit attempt than those with no workplace restrictions on smoking. This difference in our findings may have been due to the wide acceptance of smoking in Bangladeshi families and the dominating nature of smokers in the family who are mostly male. This phenomenon underscores the lack of enforcement of smoking restrictions in the home or workplace which might allow smokers to continue to smoke without affecting their quitting intentions. In a cross-sectional study of a large national sample of U.S. residents, Farkas et al. found that living in smoke-free households and working in smokefree workplaces had significant impacts on cessation [24].

The finding that recent quitting efforts (tried to quit less than six months ago) were associated with increased quitting success compared to making an attempt six months ago or earlier, is of note. These findings are most likely due to differences in smokers' readiness to quit, while recent quitters try again and smokers without a recent quit attempt may simply not be ready to quit currently and thus not try to quit. This suggests the need to encourage smokers to make frequent quit attempts that should also reinforce their confidence to quitting, regardless of perceived likelihood of success on that quit attempt. In a study by Borland et al. [14] study, motivational factors predicted quit attempts but not maintenance of smoking cessation.

Consistent with the findings from other studies [25], perceiving one's health as good or excellent was positively associated with quit success. This is due to the fact that those who are in good perceived health status practice more healthy behaviors and possess greater perceived benefits of quitting smoking. This group of people is more aware of the health risks of smoking and has high perceived vulnerability [26], which might mediate their quitting success. This underscores the need to incorporate risk perception as a construct within the population-based smoking cessation intervention programs.

The study has several limitations. First, our analysis was limited to daily smokers only, therefore, the findings may not be applicable to non-daily smokers. However, according to Wave 1 data, $96.1 \%$ of cigarette smokers/ dual users smoke cigarettes daily and $94.4 \%$ of dual users smoke bidis daily, thus our results are representative for the vast majority of smokers in Bangladesh. Second, we limited successful quitters to those who quit for more than 6 months at the time of data collection, but some people will relapse [27], and thus our analysis probably included some people who did not quit permanently. Third, we were not able to examine the impact of using pharmacological therapy (i.e. nicotine replacement therapy or medications), if any, because the information was unavailable in the data set. Studies have reported that the use of such therapy predict quitting [28]. However, given the fact that these products were 
not registered and unavailable in Bangladesh at the time of the study, the probability of using these products by the respondents was very low. Fourth, because of the self-reported nature of smoking status, smoking could be underreported due to the respondents' wish to give a socially desirable response $[29,30]$. However, there is evidence that self-reports and biochemical measurements of serum cotinine concentration provide similar estimates of smoking prevalence in the United States [31]. Fifth, most of the earlier literature reported nicotine dependence as a predictor for smoking cessation $[19,20,32]$. However, we were unable to include nicotine dependence as a predictor of quitting attempts or smoking cessation due to the way data was collected in Wave 1 . We did try to compensate for this by using CPD (total number of cigarettes smoked per day) and perceived addiction as predictors, although they were dropped from the model. It might be the case that a single measure such as nicotine dependence would have been better in this case. Finally, data were collected by trained interviewers who followed written interviewer guidelines. Any difference between their understanding and explanation of the questions asked could result in bias in information collected. However, such bias was minimized by the periodical observation of interviews by the senior research team members and investigator's biweekly meetings with the interviewers.

In conclusion, the present study identified several predictors of quitting attempts and successful quitting amongst adult Bangladeshi smokers. The promoters of smoking cessation services should consider these factors when designing comprehensive tobacco control initiatives and in service planning. This could be done by identifying smokers who are not making any quitting attempt or were more likely to be unsuccessful in their quitting attempt, and then promoting targeted interventions for these groups of smokers. Our results call for an integrated intervention approach to promote smoking cessation at the population level which should target both social environmental and individual level factors. Efforts to intervene in quitting behavior (i.e. attempt to quit and smoking cessation) will have limited effectiveness unless they take into account the social environmental context in which such behavior takes place.

\section{Abbreviations \\ ITC: International Tobacco Control Policy Evaluation Project; BDT: Bangladeshi Taka; WHO: World Health Organization; AIC: Akaike information criterion; USDHHS: U.S. Department of Health and Human Services.}

\section{Competing interests}

The authors declare that they have no competing interests.

\section{Authors' contributions}

GTF, NN, ASA planned the study. ACKQ coordinated the overall implementation of the project. NN directed the project implementation and field work in Bangladesh. ASA took the lead to draft the paper. PD conducted all the analyses and gave critical comments on the initial drafts. All authors approved the final draft of the paper.

\section{Acknowledgements}

The authors would like to acknowledge the team members from University of Waterloo and University of Dhaka for their contributions in the ITC Bangladesh Project. The ITC Bangladesh Project was supported by the International Development Research Centre (IDRC Grant 104831-002), Canadian Institutes for Health Research (Operating Grants 79551 and 115016), the US National Cancer Institute (P01 CA138389). Additional support was provided to Geoffrey T. Fong from a Senior Investigator Award from the Ontario Institute for Cancer Research and a Prevention Scientist Award from the Canadian Cancer Society Research Institute. ASA was supported by a Clinical Innovator Award from the Flight Attendant Medical Research Institute, USA through a grant to the American Academy of Pediatrics (AAP) Julius B. Richmond Center.

\section{Author details}

'Department of General Internal Medicine, Boston Medical Center, Boston University School of Medicine, 801 Massachusetts Avenue, 2nd Floor (MISU), Boston, Massachusetts 02118, USA. ${ }^{2}$ Global Health Program, Duke Kunshan University, Kunshan, Jiangsu Province 215347, China. ${ }^{3}$ Duke Global Health Institute, Duke University, Durham, NC 27710, USA. ${ }^{4}$ Department of Psychology, University of Waterloo, Ontario, Canada. ${ }^{5}$ Department of Economics, University of Dhaka, Dhaka, Bangladesh. ${ }^{6}$ Ontario Institute for Cancer Research, Toronto, Ontario, Canada.

Received: 27 April 2015 Accepted: 5 August 2015

Published online: 11 August 2015

\section{References}

1. World Health Organization (WHO). WHO report on the global tobacco epidemic, 2008. The MPOWER Package. Geneva, Switzerland: World Health Organization, 2008. Available at http://www.who.int/tobacco/mpower/ mpower_report_full_2008.pdf. Accessed on May 26, 2010.

2. U.S. Department of Health and Human Services (USDHHS). Reducing tobacco use: A report of the surgeon general. Atlanta, GA: Public Health Service, Centers for Disease Control and Prevention, National Center for Chronic Disease Prevention and Health Promotion, Office on Smoking and Health. USDHHS; 2000.

3. WHO. 2009. Global adult tobacco survey (GATS): Bangladesh. World Health Organization. Available from: http://www.searo.who.int/LinkFiles/ Regional_Tobacco_Surveillance_System_GATSBAN_FullReport2009.pdf

4. ITC Project (June 2011). ITC Bangladesh Wave 2 Technical Report. University of Waterloo, Waterloo, Ontario, Canada, and University of Dhaka, Dhaka, Bangladesh. http://itcproject.org/files/Report_Publications/Technical_Report/ bd2trfinaljun17.pdf.

5. World Health Organization (WHO). Impact of tobacco-related illnesses in Bangladesh. New Delhi, India: World Health Organization, South East Asia Region; 2007.

6. Alam DS, Jha P, Ramasundarahettige C, et al. Smoking-attributable mortaility in Bangladesh : proportional mortality study. Bull World Health Organ. 2013;91:757-64.

7. Jolicoeur DG, Ahluwalia JS, Richter KP, et al. The use of nicotine patches with minimal intervention. Prev Med. 2000;30:504-12.

8. Town Gl, Fraser P, Graham S, et al. Establishment of a smoking cessation programme in primary and secondary care in Canterbury. N Z Med J. 2000;113:117-9.

9. Freund KM, D'Agostino RB, Belanger AJ, et al. Predictors of smoking cessation: the framingham study. Am J Epidemiol. 1992;135:957-64.

10. Yang T, Abdullah AS, Mustafa J, Chen B. Factors associated with smoking cessation among Chinese adults in rural China. Am J Health Behavior. 2009;33(2):125-34.

11. Fong GT, Cummings KM, Borland R, Hastings G, Hyland A, Giovino G, et al. The conceptual framework of the International Tobacco Control (ITC) policy evaluation project. Tob Control. 2006;15:13-11. doi:10.1136/tc.2005.015438.

12. Abdullah AS, Hitchman SC, Driezen P, Nargis N, Quah AC, Fong GT. Socioeconomic differences in exposure to tobacco smoke pollution (TSP) in Bangladeshi households with children: findings from the International Tobacco Control (ITC) Bangladesh Survey. Int J Environ Res Public Health. 2011;8(3):842-60. 
13. ITC Project (April 2010). ITC Bangladesh Wave 1 Technical Report. University of Waterloo, Waterloo, Ontario, Canada, and University of Dhaka, Dhaka, Bangladesh. http://itcproject.org/files/Report_Publications/National_Report/ bd1trfinalapr21.pdf.

14. Borland $\mathrm{R}$, Yong $\mathrm{H}-\mathrm{H}$, Balmford J, et al. Motivational factors predict quit attempts but not maintenance of smoking cessation: Findings from the International Tobacco Control Four country project. Nicotine Tob Res. 2010;12 Suppl 1:S4-S11.

15. Yang G, Ma J, Chen A, et al. Smoking cessation in China: findings from the 1996 national prevalence survey. Tob Control. 2001;10:170-4.

16. Hymowitz N, Cummings MK, Hyland A, Lynn WR, Pechacek TF, Hartwell TD. Predictors of smoking cessation in a cohort of adult smokers followed for five years. Tob Control. 1997;6 suppl 2:S57-62.

17. Hatziandreu EJ, Pierce JP, Lefkopoulou M, et al. Quitting smoking in the United States in 1986. J Natl Cancer Inst. 1990;82:1402-6.

18. Tucker JS, Ellickson PL, Orlando M, et al. Predictors of attempted quitting and cessation among young adult smokers. Prev Med. 2005;41:554-61.

19. Abdullah AS, Yam HK. Intention to quit smoking, attempts to quit, and successful quitting among Hong Kong Chinese smokers: population prevalence and predictors. Am J Health Promot. 2005;19(5):346-54.

20. Abdullah AS, Ho LM, Kwan YH, Cheung WL, McGhee SM, Chan WH. Promoting smoking cessation among the elderly: what are the predictors of intention to quit and successful quitting? Aging Health. 2006;18(4):552-64.

21. Abdullah AS, Lam TH, Chan SK, Leung GM, Chi I, Ho WW, et al. Effectiveness of a mobile smoking cessation service in reaching elderly smokers and predictors of quitting. BMC Geriatr. 2008;8:25. doi:10.1186/1471-2318-8-25.

22. Haas JS, Linder JA, Park ER, Gonzalez I, Rigotti NA, Klinger EV, et al. Proactive tobacco cessation outreach to smokers of low socioeconomic status: a randomized clinical trial. JAMA Intern Med. 2015;175(2):218-26. doi:10.1001/ jamainternmed.2014.6674.

23. Siahpush M, Borland R, Scollo M. Factors associated with smoking cessation in a national sample of Australians. Nicotine TobRes. 2003;4:597-602.

24. Farkas JA, Gilpin EA, Distefan MJ, Pierce JP. The effects of household and workplace smoking restrictions on quitting behaviors. Tob Control. 1999;8:261-5.

25. Weinberger AH, Mazure CM, McKee SA. Perceived Risks and Benefits of Quitting Smoking in Non-Treatment Seekers. Addict Res Theory. 2010;18(4):456-63. doi:10.3109/16066350903145072.

26. Borrelli B1, Hayes RB, Dunsiger S, Fava JL. Risk perception and smoking behavior in medically ill smokers: a prospective study. Addiction. 2010 Jun;105(6):1100-8. doi: 10.1111/j.1360-0443.2010.02900.x

27. Murray RP, Gerald LB, Lindgren PG, Connett JE, Rand CS, Anthonisen NR. Characteristics of participants who stop smoking and sustain abstinence for 1 and 5 years in the Lung Health Study. Prev Med. 2000;30:392-400.

28. Fiore MC, Bailey WC, Cohen SJ, et al. Treating Tobacco Use and Dependence, Clinical Practice Guideline. Rockville, Md: Public Health Service; 2000.

29. Patrick DL, Cheadle A, Thompson DC, Diehr P, Koepsell T, Kinne S. The validity of self-reported smoking: a review and meta-analysis. Am J Public Health. 1994;84:1086-93.

30. Klebanoff MA, Levine RJ, Clemens JD, DerSimonian R, Wilkins DG. Serum cotinine concentration and self-reported smoking during pregnancy. Am J Epidemiol. 1998;148:259-62.

31. Caraballo RS, Giovino GA, Pechacek TF, Mowery PD. Factors associated with discrepancies between self-reports on cigarette smoking and measured serum cotinine levels among persons aged 17 years or older: Third National Health and Nutrition Examination Survey, 1988-1994. Am J Epidemiol. 2001:153:807-14.

32. Hyland A, Borland R, Li Q, Yong H-H, MCNeill A, Fong GT, et al. Individuallevel predictors of cessation behaviours among participants in the International Tobacco Control (ITC) Four Country Survey. Tob Control. 2006;15:83-94. doi:10.1136/tc.2005.013516.

\section{Submit your next manuscript to BioMed Central and take full advantage of:}

- Convenient online submission

- Thorough peer review

- No space constraints or color figure charges

- Immediate publication on acceptance

- Inclusion in PubMed, CAS, Scopus and Google Scholar

- Research which is freely available for redistribution

Submit your manuscript at www.biomedcentral.com/submit 